\title{
Developing a diabetes prevention education programme for community health-care workers in Thailand: formative findings
}

\author{
Kitti Sranacharoenpong ${ }^{1}$ and Rhona M. Hanning ${ }^{2}$ \\ ${ }^{1}$ Institute of Nutrition, Mahidol University, Nakhon Pathom, Thailand \\ ${ }^{2}$ Department of Health Studies and Gerontology, University of Waterloo, Waterloo, Canada
}

\begin{abstract}
Aims: The aim of this study was to investigate barriers to and supports for implementing a diabetes prevention education programme for community health-care workers (CHCWs) in Chiang Mai province, Thailand. The study also aimed to get preliminary input into the design of a tailored diabetes prevention education programme for $\mathrm{CHCWs.} \mathrm{Background:} \mathrm{Thailand} \mathrm{has} \mathrm{faced} \mathrm{under-nutrition} \mathrm{and} \mathrm{yet,} \mathrm{paradoxically,}$ the prevalence of diseases of over-nutrition, such as obesity and diabetes, has escalated. As access to diabetes prevention programme is limited in Thailand, especially in rural and semi-urban areas, it becomes critical to develop a health information delivery system that is relevant, cost-effective, and sustainable. Methods: Health-care professionals $(n=12)$ selected from health centres within one district participated in in-depth interviews. In addition, screened people at risk for diabetes participated in interviews ( $n=8$ ) and focus groups ( $n=4$ groups, 23 participants). Coded transcripts from audiotaped interviews or focus groups were analysed by hand and using NVivo software. Concept mapping illustrated the findings. Finding: Health-care professionals identified potential barriers to programme success as a motivation for regular participation, and lack of health policy support for programme sustainability. Health-care professionals identified opportunities to integrate health promotion and disease prevention into $\mathrm{CHCWs}^{\prime}$ duties. Health-care professionals recommended small-group workshops, hands-on learning activities, case studies, and video presentations that bring knowledge to practice within their cultural context. $\mathrm{CHCWs}$ should receive a credit for continuing study. People at risk for diabetes lacked knowledge of nutrition, diabetes risk factors, and resources to access health information. They desired two-way communication with $\mathrm{CHCWs}$. Formative research supports the need for an effective, sustainable programme to support knowledge translation to $\mathrm{CHCWs}$ and at-risk populations in the communities they serve. Ultimately, this should support chronic disease prevention in Thailand.
\end{abstract}

Key words: community health-care workers; diabetes prevention programme; health promotion; Thailand

Received 3 September 2010; accepted 18 April 2011; first published online 22 June 2011

Correspondence to: Dr Kitti Sranacharoenpong, $\mathrm{PhD}$, Institute of Nutrition, Mahidol University, Phuttamonthon 4, Salaya, Phuttamonthon, Nakhon Pathom 73170, Thailand. Email: nuksn@mahidol.ac.th

\section{Introduction}

Type 2 diabetes and its complications have become a major health concern in Thailand as a result of rapid economic, lifestyle, and nutritional change in recent decades (Kim et al., 2001; Aekplakorn et al., 2006). Research evidence indicates that type 2 
diabetes can be delayed or prevented with lifestyle modifications (Knowler et al., 2002). Type 2 diabetes and obesity have mainly been treated at the individual level and the success of such interventions has been poor (Glenny et al., 1997). Prevention is more effective than intervention for those who are already obese or have diabetes (Schulz et al., 2005; Hossain et al., 2007). Moreover, the need for preventive action at community, interpersonal, family, organisational, regional, and societal levels has never been greater as countries face the near-epidemic rise of these conditions.

The Thai Ministry of Public Health (MOPH) has developed and implemented a public health policy with the introduction of health promotion programmes nationwide. Although particular health promotion programmes, such as family planning or immunisation services, have been successful, others such as traffic accident prevention, smoking cessation, campaigns against liver cancer, and chronic disease prevention have not been proven to be effective or sustainable (Lyttleton, 1996; Wibulpolprasert, 2007). In general, health promotion programmes are only effective when health practitioners have to follow policy decisions or when they are financed by both government and non-government organisations (Wibulpolprasert, 2000; 2007). Some programmes are also short term in practice because responsible health-care personnel have to turn their attention to new policies. There is no research to guide the development of a community-based diabetes prevention programme in Thailand. It may be that such an intensive programme requires resources beyond the reach of most communities. The Thai health-care system and its activities are not focused on diabetes prevention for the at-risk population. Health-care providers are unaware of the need for diabetes prevention and of the positive outcomes of such programmes (Wibulpolprasert, 2000).

Community health-care workers $(\mathrm{CHCWs})$ are defined as members of a particular community who work as a bridge between the primary health-care system and the community members (Wibulpolprasert, 2000). To help foster the role of CHCWs as change agents and effectively integrate their work into the health system, continuing education that respects the roles, skills, and contributions of the CHCWs are essential (Witmer et al., 1995; Hill et al., 1996; Satterfield et al., 2002).
One effective approach to health promotion is to use CHCWs as facilitators to bring health information directly to the target populations (Witmer et al., 1995). Although there is not a lot of research specific to CHCWs, a Cochrane review found that training enhanced effectiveness of CHCWs (Briggs and Garner, 2006). They cited studies in Tanzania (Armstrong et al., 2004) and Bangladesh (Arifeen et al., 2004). The World Health Organisation's (WHO, 1996; 1997) health education strategy of providing an extensive 11-14-day training course in the integrated management of childhood illness for health-care workers showed improvements in assessment, treatment, and counselling. It also reduced childhood mortality in Tanzania (Armstrong et al., 2004).

Various theories and models of behaviour change and social ecology may inform obesity and type 2 diabetes prevention; however, as reviewed by Baranowski et al. (2003), no single model can fully guide prevention efforts. Nevertheless, 'promising concepts' derived from these models may be helpful in better understanding behaviours and structuring programmes. Strategies that address determinants of behaviour at a variety of ecological levels should be considered.

Therefore, the objectives of the study were to investigate barriers to and support for implementing a community-based diabetes prevention education programme for $\mathrm{CHCWs}$ and to get preliminary input into programme design from the perspectives of health-care professionals and potential programme recipients of Chiang Mai province, Thailand.

\section{Methods}

The Office of Research Ethics at the University of Waterloo, Ontario, Canada; Mahidol University, Nakhon Pathom province, Thailand; and the Office of Disease Prevention and Control, Ministry of Public Health, Thailand, granted permission to conduct the study.

\section{Setting}

This phase of the study was conducted in San Sai district in Chiang Mai province, Thailand. San Sai district is a semi-urban area that is not far from the city of Chiang Mai. People of the community are mainly labourers at factories or 
companies. The area has less than $50 \%$ agricultural households. This is reflected in the economy and typical socio-economic status of the district and Chiang Mai province (United Nations Development Programme, 2007). The incidence of obesity and new cases of diabetic patients have been increasing over time (Wibulpolprasert, 2007). The risk factors for diabetes have been linked to obesity, lifestyle changes, increased dietary fat intake, reduced fibre intake and physical inactivity, and socio-economic status (Aekplakorn et al., 2006). Health-care centres are part of the primary health-care systems that are located close to the community where people live. Health-care centres provide basic health care, including health promotion, disease and illness prevention, and treatment of common health problems. They also offer a holistic continuum of care in healthy, high-risk, minor illness, and chronic illness/conditions (Hanucharurnkul, 2007). Health-care centres run health programmes according to the standard operational procedures established by the MOPH, under the technical supervision and support of the community hospital (Wibulpolprasert, 2002; 2007). Roles of Thai CHCWs, health personnel, or general practitioners for health promotion are included in the primary health-care system (Wibulpolprasert, 2007). The components of the primary care system are as follows: a community health post is a village-level health service unit established specifically in remote areas, covering a population of 500-1000, and staffed by only one CHCW (a permanent employee of the MOPH). A health-care centre is a sub-district or village-level health service unit, covering a population of about 1000-5000 with health staff, a midwife, a technical nurse, and/or a CHCW.

\section{Study design}

The formative phase comprised a 10-day observation at one health-care centre; in-depth interviews with health-care professionals; and in-depth interviews and focus groups with people at risk for diabetes.

\section{Observation}

The observation was conducted during regular working hours of the health-care centre from 9am to $4 \mathrm{pm}$ for 10 days. The purpose of the observation was to gather health-care information, and to understand the diabetes prevention and health promotion situation at the community level. Information from the observations and informal talks with the health-care staff were noted, such as the role of each health-care professional (three to four staff), routine work, activities, and home visiting. The information was used to develop in-depth interviews and focus group guidelines.

\section{Health-care professionals}

In-depth interviews were run for health-care professionals (doctors and nurses) and $\mathrm{CHCWs}$ who worked at the health-care centres. A purposive selection strategy was used to identify key informant participants for in-depth interviews. The average age of 12 professionals was 45 years, and $83 \%$ of them had more than 10 years of work experience in public health (Table 1). The health-care professionals participated in in-depth interviews to explore the attitudes, awareness, and experiences towards diabetes prevention and related risk factors in the community. Interviews were used to gather information on demographics, prominent health concerns, gaps in services, experience with current training, support service needs, and perceived support for an innovative training programme suited for the Thai health-care system.

\section{People at risk for diabetes}

The in-depth interviews and focus groups of people at risk for diabetes were conducted to understand their behaviour, beliefs, practices, and knowledge of health promotion and disease prevention. A mix of approaches was used in case people might be more forthcoming in an individual versus group setting. The desire was to select adults, that is, both men and women, who were at risk for diabetes but were not yet diagnosed with diabetes based on Aekplakorn's criteria (Aekplakorn et al., 2006). Purposive sampling involved four health-care centres and their at-risk community members. Health-care professionals and researchers worked together for at-risk member selection. The sample of people at risk for diabetes from San Sai district was recruited from the diabetes screening database. Community members were systematically screened by $\mathrm{CHCWs}$ and nurses at the community health-care centres for eligibility via the diabetes risk score 
Table 1 General information of health professionals and people at risk for diabetes

\begin{tabular}{|c|c|c|}
\hline & $\begin{array}{l}\text { Health professionals } \\
(n=12)\end{array}$ & $\begin{array}{l}\text { People at risk for } \\
\text { diabetes }(n=31)\end{array}$ \\
\hline \multicolumn{3}{|l|}{ Gender } \\
\hline Male $(n, \%)$ & $2(17)$ & $14(45)$ \\
\hline Female $(n, \%)$ & $10(83)$ & $17(55)$ \\
\hline \multicolumn{3}{|l|}{ Education $(n, \%)$} \\
\hline Bachelor degree & $9(75)$ & - \\
\hline Less than bachelor degree & $3(25)$ & _- \\
\hline More than grade 4 & - & $4(16)$ \\
\hline Grade 4 & - & $26(84)$ \\
\hline Age, years (Mean $\pm S D$ ) & $44.5 \pm 3.5$ & $52.2 \pm 5.6$ \\
\hline \multicolumn{3}{|l|}{ Occupation $(n, \%)$} \\
\hline Doctor & $2(17)$ & - \\
\hline Nurse & $5(41.5)$ & - \\
\hline CHCWs & $5(41.5)$ & - \\
\hline Government staff & - & $1(3)$ \\
\hline Agriculture & - & $8(26)$ \\
\hline Labourer & - & $14(45)$ \\
\hline Own business & - & $4(13)$ \\
\hline Housewife & _- & $4(13)$ \\
\hline \multicolumn{3}{|l|}{ Work experience, year $(n, \%)$} \\
\hline$<10$ years & $2(17)$ & - \\
\hline$>10$ years & $10(83)$ & - \\
\hline \multicolumn{3}{|l|}{ BMI } \\
\hline Overweight $(\geqslant 23-\leqslant 27.5 ; n, \%)^{a}$ & - & $14(45)$ \\
\hline Obesity ( $\geqslant 27.5 ; n, \%)$ & - & $10(32)$ \\
\hline \multicolumn{3}{|l|}{ Waist circumference } \\
\hline Male $(\geqslant 90 \mathrm{~cm})$ & - & $4(13)$ \\
\hline Female $(\geqslant 80 \mathrm{~cm})$ & _- & $13(42)$ \\
\hline Hypertension $(n, \%)$ & - & $22(71)$ \\
\hline Family history of type 2 diabetes $(n, \%)$ & _ & $25(81)$ \\
\hline \multicolumn{3}{|l|}{ Diabetes risk score } \\
\hline Median (min, $\max$ ) & - & $11(6,17)$ \\
\hline Mean \pm SD & - & $11.35 \pm 2.76$ \\
\hline
\end{tabular}

$\mathrm{CHCWs}=$ community health-care workers; $\mathrm{BMI}=$ body mass index.

${ }^{a}$ WHO Expert Consultation (2004).

for Thais. The risk factors for screening were age, sex, body mass index, waist circumference, hypertension, and history of diabetes in a parent or sibling. A cut-off point of the risk score for predicting high five-year risk of diabetes in Thais was six. A score below six indicates low risk of diabetes (Aekplakorn et al., 2006). All community members had not yet scored as diabetic patients and hence did not take medications to control their blood sugar. Nurses and $\mathrm{CHCWs}$ identified people known to the centre, who they felt would be able and willing to participate and would provide broader perspectives. Initial contact and appointments were made with people at risk for diabetes through the community healthcare centres by an invitation letter. The details of the study, objectives of interviewing, and consent letters were sent to the participants before the interview and focus group discussions.

In all, eight people at risk of developing diabetes participated in in-depth interviews and 23 people participated in focus groups $(n=4$ groups). The average age was 52 years and $84 \%$ of them had graduated from grade 4 level (Table 1). Half of them were labourers in this semi-urban community. Those selected had average diabetes risk scores of 11 . More than $80 \%$ of them had a family history of type 2 diabetes. The researchers explored the attitudes, beliefs, practices, gaps in health-care service, barriers to and opportunities for health promotion for people at risk for diabetes in the community towards the prevention of type 2 diabetes. 


\section{Data collection}

Interview and focus group guidelines were developed from the health centre observation to elicit information from participants. Thai interview guidelines were discussed among provincial health-care professionals before implementing them. Minor changes were made to the interview guide to ensure that the questions worked in an open-ended format. The guidelines included an introduction that explained the purpose of the interview and requested permission to audio-tape the interview. A researcher conducted all interviews and focus groups at health-care centres in the communities. Interviews and focus groups averaged $90 \mathrm{~min}$ in length (range 60-150 min), and were tape-recorded with the consent of the participants. Then, participants were asked a series of open-ended questions and encouraged to share their perspectives. All interviews and focus groups were conducted face to face in an informal manner. The interviews preceded the focus group in each community. The interviewer probed participants to obtain additional information on interesting topics that emerged, in order to clarify ambiguous comments. The research assistant took notes during the focus groups.

\section{Data analysis}

A team of Thai research assistants fluent in the local language transcribed in-depth interview and focus group discussions from the audio tape. The data sources for the analysis were transcripts of interview tapes and a synthesis of the interviewers' debriefing notes made during the interviews/focus groups, including expanded summary notes made immediately following each interview/focus group. A sample of four translations was independently checked for accuracy. Both the transcripts and field notes were organised by hand and using NVivo version 7 (QSR, 2006), and the content was analysed thematically. A blended coding scheme was used, consistent with both the pre-identified interview questions and the categories and themes emerging from the data during an initial process of open coding (Morse and Field, 1995; Berg, 2006). To increase reliability, the themes were confirmed by a second independent researcher who reviewed transcripts from two interviews (one professional, one community volunteer) and two focus groups. Only minor differences in interpretation were found and a consensus was acquired through discussion. Codes were constructed based on frequency, intensity, clarity, and consistency of participants' supporting statements. The units of analysis were sentences or phrases. Themes and sub-themes were identified and interrelationships depicted using concept maps. The concept maps helped the researchers to understand barriers, opportunities, and needs regarding diabetes prevention at the community level. The concept maps also helped to frame and inform the diabetes prevention education programme for CHCWs.

Hurricane thinking, as outlined by Kirby and McKenna (1989), was a useful tool in organising the themes from the interviews. Main responses and themes were identified, followed by the delimitation of irrelevant or overlapping data. The data continued to be coded into categories. Concept development was the final stage of the data analysis. This study has generated an emergent diagram of barriers to and support for diabetes prevention education programme for $\mathrm{CHCWs}$ from the data gathered from the healthcare professionals, $\mathrm{CHCWs}$, and people at risk for diabetes. Analysis of the participant interviews has provided insight into the factors that both limit and facilitate community integration for individuals with people who are at risk for diabetes. The thickness of the arrows depicts the strength of the relationship. The thicker arrows represent stronger relationships, and the thinner arrows weaker relationships. A concept map was developed to depict the relationship of the barriers to and support for a diabetes prevention education programme. In Figure 2, although the themes and categories included in the concept map are similar to the hurricane diagram, the concept map made it possible to visually distinguish themes that showed weaknesses/threats and strengths of diabetes prevention.

\section{Results}

Thematic analysis of the transcripts from the combined interviews and focus groups from both the health-care professionals and people at risk for diabetes yielded a range of input that was captured in the hurricane diagram (Figure 1). The findings of health-care professionals and at-risk 


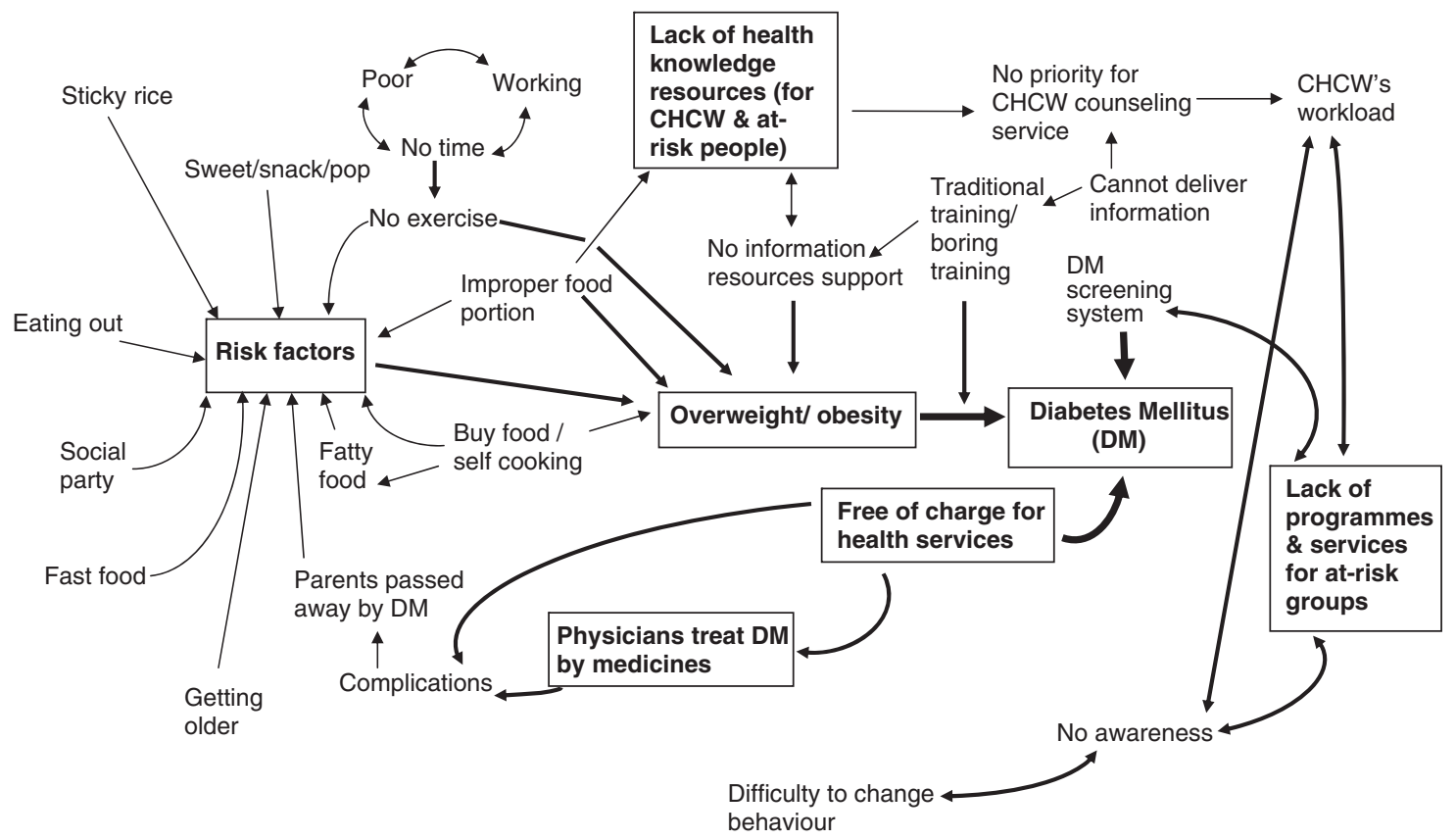

Figure 1 Hurricane diagram generated from input from health-care professionals, community health-care workers, and people at risk for diabetes.

community members overlapped and were interrelated. The analysis revealed a variety of interrelated themes and sub-themes of primarily contributing factors for a diabetes prevention programme in Chiang Mai province in Thailand. The core issue relating to diabetes for the community was being overweight and obese. Being overweight and obese were associated with other major themes, including lack of exercise, improper food portion, risk factors of overweight/obesity, and lack of information resources. Figure 1 shows the interrelationships between themes and related sub-themes. The concept map (Figure 2) depicts the narrative of findings that identifies major themes and positions them in a modified strengths, weaknesses, opportunities, and threats/ barriers analysis for a diabetes prevention education programme for $\mathrm{CHCWs}$ in Chiang Mai province, Thailand. A strength for diabetes prevention in communities is the diabetes screening system with at-risk community members. The diabetes screening system is disease surveillance and $\mathrm{CHCWs}$ report the prevalence to the MOPH. CHCWs also can educate at-risk people to be aware of diabetes. Available computers and highspeed Internet at health-care centres are one of the opportunities for CHCWs to gain knowledge by themselves. The regular short course training provides another opportunity for $\mathrm{CHCWs}$ to learn diabetes prevention. However, the weaknesses/ threats of health promotion and diabetes prevention are the health system, lack of interest to implement a diabetes programme for at-risk populations, lack of knowledge support, and lack of computer skills. The Thai health system does not support health professionals and CHCWs to promote good health for people in the community. Health-care professionals focus on treatment more than disease prevention and health promotion. The prevalence of diabetes is increasing over time, but health-care staff and CHCWs do not appear interested in implementing diabetes prevention programmes for at-risk populations in their communities. Indeed, the MOPH provides short course training for CHCWs every year, but they need knowledge resources and opportunities. Use of technologybased resources for delivering knowledge is one effective approach to support to CHCWs. However, 


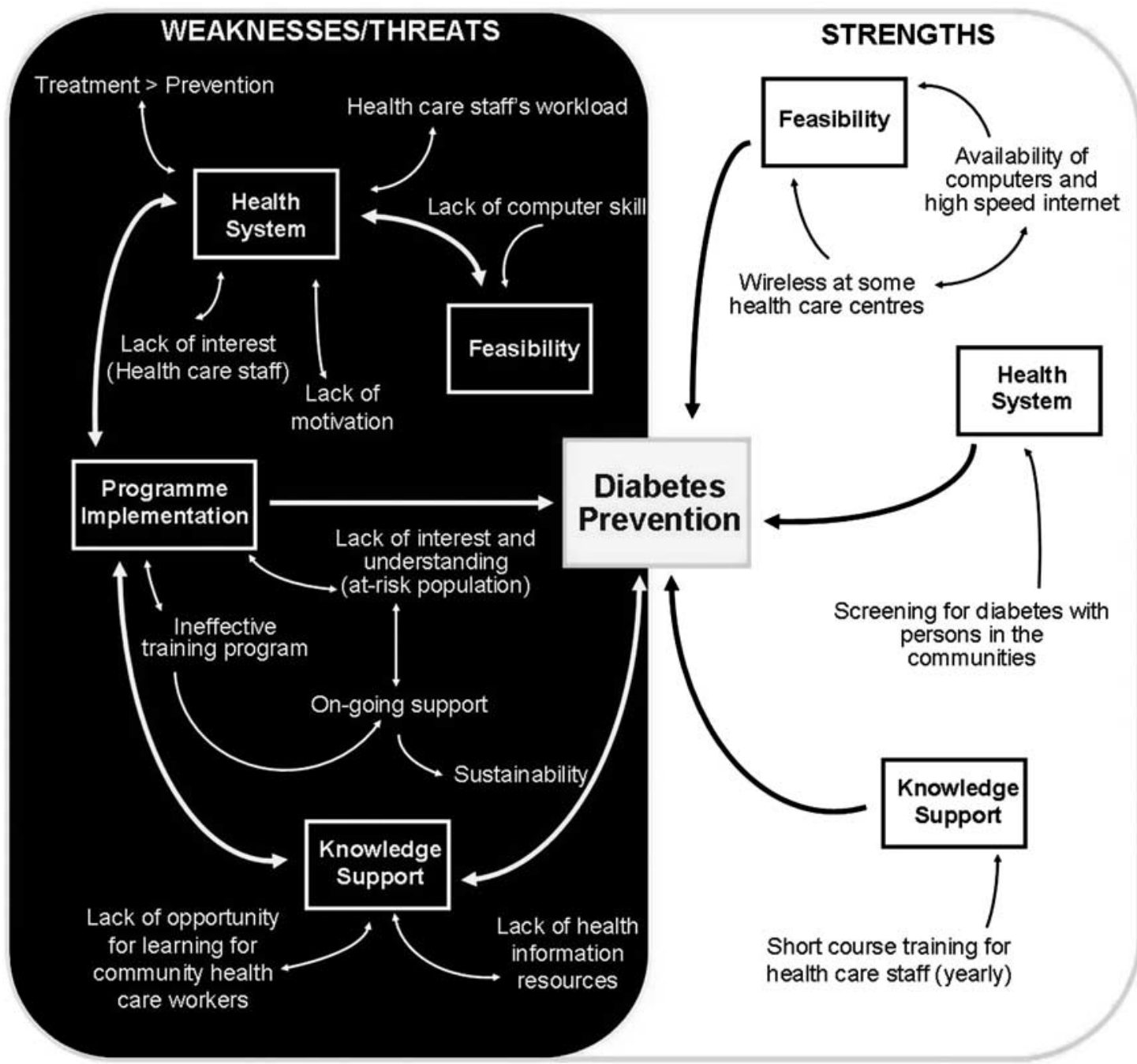

Figure 2 A concept map of barriers to and support for a diabetes prevention education programme for community health-care workers in Chiang Mai province, Thailand.

the training of computer skills is also necessary for CHCWs. In both Figures 1 and 2, the arrows are not meant to imply causality, only the relationship between categories and the directions of this relationship based on the data analysis.

\section{The health-care system}

The concept of diabetes prevention and health promotion had not yet been a concern in the health-care system even though the diabetes prevalence in Chiang Mai province has been increasing over time. Health professionals have had many responsibilities, such as focusing on treatment and their routine screening reports. They agreed that their workload did not allow them much time to focus on people with diabetes risk factors even though they have annual screening for risk factors. All health professionals agreed that they do not take any actions when they know who at-risk people with diabetes are. They focus on newly diagnosed diabetic patients 
and treatment by medications that are free of charge. Screening for diabetes and other risk factors of chronic diseases are routine work for CHCWs and staff at the health-care centres. They normally monitor once a year. Nurses and CHCWs screened for factors affecting diabetes according to a standard format from the MOPH. The minimum rate of screening was $60 \%$ of the total population aged more than 35 years reported to the MOPH annually. This activity has been included in the national health promotion policy of Thailand for the last five years (Wibulpolprasert, 2007). Unfortunately, the ministry has only service support for patients with diabetes and chronic diseases. People at risk for diabetes have no activities to help them to prevent diabetes. $\mathrm{CHCWs}$ mentioned that they did not understand the screening results, including the meaning of some of the risk factors. Nurses and CHCWs mentioned that:

I think it is hard to educate people to take care of themselves and prevent diabetes because the MOPH provides free of charge medicine. (In-depth interview doctor no. 5)

Yes, we have screening for diabetes with all people, aged 35 years old, but diabetic patients are increasing over time, I don't know how to prevent this problem. (In-depth interview nurse no. 3)

\section{Knowledge support}

Lack of learning opportunities and health information resources for nurses, $\mathrm{CHCWs}$, and people in the community came out clearly under the 'knowledge support' theme. Although the MOPH and provincial hospitals provided annual training courses, some of the health-care staff have no opportunity to attend the training. When we asked about training on diabetes prevention, respondents said that the provincial hospital provided some lectures to health-care staff, for example, a one-day symposium made up of traditional lectures. A recurring theme was that CHCWs at the health-care centres had received limited education and support on health promotion and type 2 diabetes prevention. They felt that not only did their information/knowledge provide them with an inadequate understanding and skill base, but also that it failed to prepare them for working with at-risk people in the community, who had chronic diseases including diabetes. One participant made this statement:

...the hospitals set training for us at least one time a year... I don't like the training... Nothing is new. (In-depth interview $\mathrm{CHCW}$ no. 12)

CHCWs and nurses were asked how they found/accessed information when they needed more knowledge about health, disease prevention, nutrition, or diet-related diseases. They received some support materials from the centre/ district hospitals. Some pamphlets, books, guidelines, and posters were delivered by or requested from the health offices in the province. However, some materials took a long time to arrive. A participant commented:

Well, we got materials supported from the health office in Chiang Mai, but they came when we didn't need it and some information were not fit for us. (In-depth interview CHCW no. 6)

Health-care professionals and $\mathrm{CHCWs}$ appeared to have a general knowledge that obesity, diet, and exercise are all related to developing diabetes, and that some changes in lifestyle behaviour could help prevent diabetes. They often identified categories of healthy factors, but they required prompting to describe specific factors within these categories, such as avoiding sweet, salty, and oily foods. They spoke generally about nutrition, physical activities, and even spirituality as influencing health. Some of them had searched for nutrition information about diet-related diseases on the Internet. They, however, were not sure of the reliability of the information sources. None of them liked to search and read information in English.

I tell people got risk factors for diabetes avoiding salt, sweet, and fat food...especially sticky rice (a stable food for the north people), it will increase their blood sugar. I don't know why sticky rice can cause. (In-depth interview nurse no. 4)

I think to make my own posters about diet and diabetes prevention, so I use the Google for searching. If these information look good, I copy them. (In-depth interview CHCW no. 1) 


\section{Feasibility of a diabetes prevention education programme for $\mathrm{CHCWs}$}

Computer skills of CHCWs emerged as a potential problem, although computers are not a new technology in Thailand. All health-care centres at the sub-district level have computers, hi-speed Internet access, and/or wireless. Healthcare professionals have only basic computer skills. Some of them have no individual e-mail addresses, and they do not understand technology or any key words related to the computer, such as, MSN, upload/download, Chat room, SKYPE, or conference call. Most of the health-care professionals, who were over 40 years of age, felt that computers were difficult to use. If they needed to start to learn, they would need more time and to learn it step by step. However, they not only wanted to know how the computer works, but also practice. Hence, health professionals, including $\mathrm{CHCWs}$, wanted to learn to use new technology and were open to the use of learning technology in a training programme to support their work and to prevent diabetes for at-risk people.

I seldom used computer to send e-mail. I have an assistant...can help me any things about computer. She is a technology girl. (In-depth interview $\mathrm{CHCW}$ no. 6)

No, I don't know how to chat. I just saw the chat icon, but I don't know how to use it. I have no time to chat. (In-depth interview nurse no. 3)

\section{Diabetes prevention programme implementation}

A barrier to prevent chronic disease in people at risk for diabetes in the community was lack of interest, motivation, and understanding of disease prevention. One main reason is the Thai health policy and health-care system because the government provides, free of charge, any medicine for all, even though they set health promotion as one of the policies. People at risk for diabetes did not feel concerned about food, nutrition, and exercise. They mentioned that knowledge of nutrition, diet-related diseases, and diabetes was generally provided by a relative's experience, friends, health-care professionals at the hospitals, or the media. Most participants recognised that personal lifestyle choices including diet (especially sugar, salt, and fat), excess bodyweight, and physical inactivity contributed to the development of diabetes. They saw that the condition was at least partially preventable through lifestyle change. Doctors, nurses, $\mathrm{CHCWs}$, and people believed that sticky rice, a high glycemic index staple food of the northern Thai people, could cause diabetes. They did not understand an appropriate portion size of foods and food exchange lists in each food group as recommended by Thai Flag Food Based Dietary Guidelines (Sirichakwal and Sranacharoenpong, 2008). People at risk for diabetes explained that:

When I go to the hospital, nurses tell me how many portions of rice that I should eat, but I do not understand. When I want to ask more information, nurses cannot tell me and they have no time to chat. (Focus group with people at risk for diabetes, group no. 1)

I do not understand how many portion sizes of rice that I should eat per day, no one tell me. (In-depth interview people at risk for diabetes no. 4)

Yes, I know that I should avoid sweet, salty, and fatty foods, but they are yummy. (Indepth interview people at risk for diabetes no. 5)

Health-care professionals and people at risk for diabetes suggested suitable types of implementation programmes for them, which can integrate with their ways of life in the community. Their statements included, 'We do need an exercise programme or other methods that we can know we are fit and healthy,' 'We want a health care staff that can tell there are foods we should eat and foods we shouldn't eat,' and 'Set this programme from a small group of people interested.'

Health-care professionals mentioned that a variety of health training programmes, such as HIV/AIDS, tuberculosis, and accident prevention, were available, but ineffective. Training programmes on diabetes are offered on a service basis to reinforce knowledge of health-care staff every year by the MOPH and provincial hospitals. Health-care professionals and some CHCWs attend the intensive training programme at least once a year. The format of this training was 
similar to previous training. For example, a oneday meeting was held at a hotel with speakers and their presentations or a small-group workshop; neither offer on-going support nor any contact between speakers and participants. After healthcare staff were trained by the provincial hospitals each year, they were expected to deliver knowledge to people in their communities through 'diabetes education camps' consisting of lectures and demonstrations. However, they did not do this as part of their regular work because of time constraints, budgets, knowledge supports, and lack of interest of target people.

In late every September, the ending of annual budget report, we have a lot of training programmes that want us to participate. Well, it is good if the training organisers can prepare effective training programmes. I feel waste time and budget compared with the quality of knowledge I get from the training. (In-depth interview $\mathrm{CHCW}$ no. 12)

\section{A tailored diabetes prevention programme}

Other important themes revealed from the formative research were used to inform overall diabetes education programme development. Some health-care professionals and CHCWs appeared to lack basic knowledge regarding health and healthy eating, and understanding of risk factors related to diabetes. When the researcher interviewed health-care professionals about the format of training that can support CHCWs' work, they recommended small-group workshops, hands-on learning activities, case studies, and video presentations that bring knowledge to practice within their cultural contexts. They also informed the researcher that Thai translation of the training materials was important. In the same way, people at risk for diabetes lacked knowledge of nutrition, diabetes risk factors, and resources to access health information. When they visited the hospitals or health-care centres, they desired two-way communication with $\mathrm{CHCWs}$ or nurses. When the researcher asked what needed to be in place for the programme to be successful, some health-care professionals suggested that the researchers might pay for CHCWs' time and contributions. However, others suggested that CHCWs should receive a credit for continuing study.

\section{Discussion}

This research study brought together information from community health-care professionals, people at risk for diabetes, and university researchers to investigate the potential barriers to and support for implementing a training programme for CHCWs in the semi-urban areas in Chiang Mai province, Thailand. Through interviews and focus groups, this study explored the perspectives of the participants. The findings were important and, based on data saturation, reflect the dominant concerns of participants about diabetes prevention programmes and the need for education. The interviews and focus group discussions generated a picture of the diabetes prevention situation in Thailand and the potential for programmes to support the continuing education of CHCWs and, in turn, the public. The study revealed four main barriers and three supports for a diabetes prevention education programme for CHCWs (Figure 2). The Thai MPOH has established a public health policy that mandates public health programmes across Thailand in areas such as family planning, AIDS, tuberculosis, and immunisation. Although these programmes have been successful, other programmes such as smoking cessation, campaigns against alcohol, and chronic disease prevention have not been effective and sustainable (Lyttleton, 1996; Wibulpolprasert and Pengpaibon, 2003).

It seems that health promotion programmes are only instituted in Thailand when health practitioners are mandated to implement them by government policy or when the programmes are financed by the government (Wibulpolprasert, 2000). In the same way, some programmes have not been sustained because they were run by CHCWs who have many responsibilities and have had to turn their attention to new government policies and mandated programmes. Therefore, as there are currently no government policies or mandated programmes aimed clearly at diabetes prevention, the concept of health promotion is not currently a focus for $\mathrm{CHCW}$ and other health professionals. Their work is confined to routine treatment of existing disease and, since 2004, screening for chronic disease risk factors (Wibulpolprasert and Pengpaibon, 2003; Aekplakorn et al., 2006; Wibulpolprasert, 2007).

On the other hand, the formative results also indicate some points of strength to support a 
diabetes prevention education programme for CHCWs. Some health professionals, including CHCWs, expressed concern that the incidence and prevalence of diabetic patients in their community has increased over time. Unfortunately, they have had no specific mandate to educate people about prevention or risk management. Moreover, CHCWs expressed a lack of knowledge and confidence in their ability to provide relevant advice on lifestyle. Hence, they recognised a need not only for diabetes prevention action, but also for their own education, so as to enable them to address diabetes prevention. Other supportive points that emerged from this formative study were the existence of a comprehensive, government-supported diabetes screening system, short course training at local hospitals, and the feasibility of using computers and the Internet to support $\mathrm{CHCW}$ education at the health centre level.

Together, these suggest an opportunity to build on strengths and overcome weaknesses. It seems critical that CHCWs' education about disease prevention and health promotion must be addressed. CHCWs expressed a lack of knowledge and confidence in their ability to provide relevant advice on lifestyle. Moreover, the results can serve as a guide for the learning approach, materials, and course curriculum, which will support successful implementation. Diabetes prevention education programmes delivered in community-gathering places may reach $\mathrm{CHCWs}$ who have not normally received health information/education. The use of appropriate learning approaches that serve CHCWs' needs may increase the relevance and acceptance of the programme (Sranacharoenpong et al., 2009).

Clearly, at this point in time in Thailand, the health policy and infrastructure support for $\mathrm{CHCW}$ health promotion education is not in place. It is the hope that the strong formative research conducted through this study can be used to demonstrate the feasibility and effectiveness of a diabetes prevention education programme for CHCWs. It may then be possible to better support the CHCWs, for example, through credit from the academic university for the course and for support of CHCWs' health promotion education by MOPH policy and paid training. Consulting and engaging people within their unique context are important factors for the successful implementation of programmes (Kreuter et al., 2000; Potvin et al., 2005). Broad consultation was used in the development of the programme, based on the recognition that stakeholders are more likely to accept a programme if they, or colleagues they respect, have been a part of the development phase. Successful community-based approaches to public health concerns have been addressed through coalitions of community members, academicians, and practitioners (Baker and Brownson, 1998). Moreover, local relevance is a key component of any programme. Our process was built on the experience of Baker et al. (2002) in which members of community-based programmes - including health professionals, and programme participants - helped in defining the areas of interest, the specific content, and the process of dissemination.

The formative research demonstrated that there was general support for a diabetes prevention education programme on the part of the many stakeholders who were consulted within Chiang Mai province. This was critical because input from these individuals would be necessary to further develop and, ultimately, help sustain such a programme (Buranatrevedh and Sweatsriskul, 2005; Mosavel et al., 2005). The increasing incidence and prevalence of diabetes and obesity and the importance of effectively addressing lifestylerelated diseases were undoubtedly a concern for community stakeholders at all levels. Health education to support CHCWs to work with their communities to develop and deliver culturally appropriate lifestyle interventions was seen as a priority that the study research went on to address. An innovative, tailored diabetes prevention education programme for Thai $\mathrm{CHCWs}$ was developed based on the results of formative community evaluation. The diabetes prevention education programme was designed to facilitate the learning and skill development of $\mathrm{CHCWs}$ about community-based prevention of type 2 diabetes. The course curriculum was designed to prepare CHCWs with a strong background to support activities aimed at prevention of diabetes for atrisk people, for example, those who are overweight or obese. In addition, it supported the role of $\mathrm{CHCWs}$ as communicators at the community level through skill development and resource templates. The diabetes prevention education programme was effective in improving CHCWs' health knowledge 
relevant to diabetes prevention (Sranacharoenpong et al., 2009). The innovative learning model has potential to expand chronic disease prevention training of CHCWs to other parts of Thailand. Ultimately, prevention of chronic diseases and associated risk factors should be enhanced.

\section{Acknowledgements}

This research was supported by a grant from the Nestlé Foundation, Switzerland.

The authors acknowledge the team staff of the health-care offices at San Sai district in Chiang Mai province, Thailand. The authors particularly thank Dr Saowanee Wiboolsanti, Ms Nittaya Rawangpan, and team staff of The Office of Disease Prevention and Control 10 Chiang Mai province, Ministry of Public Health for their facilities and hospitality. The authors would like to thank Ms Julia Verhaeghe for editing the English language.

Competing interests: The authors declare that they have no competing interests.

\section{References}

Aekplakorn, W., Bunnag, P., Woodward, M., Sritara, P., Cheepudomwit, S., Yamwong, S., Yipintsoi, T. and Rajatanavin, R. 2006: A risk score for predicting incident diabetes in the Thai population. Diabetes Care 29, 1872-77.

Arifeen, S.E.I., Blum, L.S., Hoque, D.M.E., Chowdhury, E.K., Khan, R., Black, R.E., Victora, C.G. and Bryce, J. 2004: Integrated management of childhood illnesses (IMCI) in Bangladesh: early findings of a cluster-randomised study. The Lancet 364, 1595-602.

Armstrong, S.J.R., Adam, T., Mshinda, H., Masanja, H., Kabadi, G., Mukasa, O., John, T., Charles, S., Nathan, R., Wilczynska, K., Mgalula, L., Mbuya, C., Mswia, R., Manzi, F., de Savigny, D., Schellenberg, D. and Victora, C. 2004: Effectiveness and cost of facility-based Integrated Management of Childhood Illness (IMCI) in Tanzania. The Lancet 364, 1583-94.

Baker, E.A. and Brownson, C.A. 1998: Defining characteristics of community-based health promotion programmes. Journal of Public Health Management and Practice 4, 1-9.

Baker, E.A., Kreuter, M., Homan, S.M., Starkloff-Morgan, S., Schonhoff, R. and Francioni, A. 2002: A using communitybased participatory processes to bring health education technology to communities. Health Promotion Practice 3, 83-94.

Primary Health Care Research \& Development 2011; 12: 357-369
Baranowski, T., Cullen, K.W., Nicklas, T., Thompson, D. and Baranowski, J.C. 2003: Are current health behavior change models helpful in guiding prevention of weight gain efforts? Obesity Research 11, 235S-43S.

Berg, B.L. 2006: Qualitative research methods for the social sciences, fourth edition. Boston: Allyn \& Bacon.

Briggs, C.J., and Garner, P. 2006: Strategies for integrating primary health services in middle- and low-income countries at the point of delivery. Cochrane Database of Systematic Reviews 2. Art. No. CD003318.

Buranatrevedh, S. and Sweatsriskul, P. 2005: Model development for health promotion and control of agricultural occupational health hazards and accidents in Pathumthani, Thailand. Industrial Health 43, 669-76.

Glenny, A.M., O'Meara, S., Melville, A., Sheldon, T.A. and Wilson, C. 1997: The treatment and prevention of obesity: a systematic review of the literature. International Journal of Obesity 21, 715-37.

Hanucharurnkul, S. 2007: Nurses in primary care and the nurse practitioner role in Thailand. Contemporary Nurse 26, 83-93.

Hill, M.N., Bone, L. and Butz, A.M. 1996: Enhancing the role of community-health workers in research. Journal of Nursing Scholarship 28, 221-26.

Hossain, P., Kawar, B. and Nahas, M.E.I. 2007: Obesity and diabetes in the developing world - a growing challenge. New England Journal of Medicine 356, 213-15.

Kim, S., Moon, S. and Popkin, B.M. 2001: Nutrition transition in the Republic of Korea. Asia Pacific Journal of Clinical Nutrition 10, S48-56.

Kirby, S.L. and McKenna, K. 1989: Chapter 6, Preparing for and doing analysis. In Kirby, S.L. and McKenna, K., editors, Experience research social change. Toronto: Garamond Press, 128-57.

Knowler, W.C., Barrett-Connor E., Fowler S.E., Hamman R.F., Lachin, J.M., Walker, E.A., Nathan, D.M. and Diabetes Prevention Programme Research Group. 2002: Reduction in the incidence of type 2 diabetes with lifestyle intervention or metformin. The New England Journal of Medicine 346, 393-403.

Kreuter, M.W., Oswald, D.L., Bull, F.C. and Clark, E.M. 2000: Are tailored health education materials always more effective than non-tailored materials? Health Education Research 15, 305-15.

Lyttleton, C. 1996: Health and development: knowledge systems and local practice in rural Thailand. Health Transition Review 6, 25-48.

Morse, J.M. and Field, P.A. 1995: Qualitative research methods for health professionals, second edition. Thousand Oaks, CA: Sage Publications.

Mosavel, M., Simon, C., van Stade, D. and Buchbinder, M. 2005: Community-based participatory research (CBPR) in South Africa: engaging multiple constituents to shape the research question. Social Science Medicine 61, 2577-587.

Potvin, L., Gendron, S., Bilodeau, A. and Chabot, P. 2005: Integrating social theory into public health practice. American Journal of Public Health 95, 591-95. 
QSR International Pty Ltd. 2006: Nvivo: Reference guide. Doncaster Victoria, Australia: Author.

Satterfield, D.W., Burd, C., Valdez, H.G. and Eagle, S.J. 2002: The in-between people: participation of community health representatives in diabetes prevention and care in American Indian and Alaskan Native communities. Health Promotion Practice 3, 166-75.

Schulz, A.J., Zenk, S., Odoms-Young, O., Hollis-Neely, T., Nwankwo, R., Lockett, M., Ridella, W. and Kannan, S. 2005: Healthy eating and exercising to reduce diabetes: exploring the potential of social determinants of health frameworks with the context of community-based participatory diabetes prevention. American Journal of Public Health 95, 645-51.

Sirichakwal, P.P. and Sranacharoenpong, K. 2008: Practical experience in development and promotion of food-based dietary guidelines in Thailand. Asia Pacific Journal of Clinical Nutrition 17, S63-65.

Sranacharoenpong, K., Hanning, R.M., Sirichakwal, P.P. and Chittchang, U. 2009: Process and outcome evaluation of a diabetes prevention education programme for community health care workers in Thailand. Education for Health 22, $335-46$.

United Nations Development Programme. 2007: Thailand Human Development Report 2007: sufficiency economy and human development. Retrieved 7 April 2009 from http://78.136.31.142/en/reports/nationalreports/asiathepacific/ thailand/ THAILAND_2007_en.pdf
Wibulpolprasert, S. (editor) 2000: Thailand health profile 1997-1998. Bangkok: Express Transportation Organisation Printing Press.

Wibulpolprasert, S. (editor) 2002: Thailand health profile 2001-2004. Bangkok: Express Transportation Organisation Printing Press.

Wibulpolprasert, S. (editor) 2007: Thailand health profile 2005-2007. Bangkok: Express Transportation Organisation Printing Press.

Wibulpolprasert, S. and Pengpaibon, P. 2003: Integrated strategies to tackle the inequitable distribution of doctors in Thailand: four decades of experience. Human Resources for Health 12, 1-17.

Witmer, A., Seifer, S.D., Finocchio, L., Leslie, J. and O'Neil, E.H. 1995: Community health workers: integral members of the health care work force. American Journal of Public Health 85, 1055-58.

World Health Organisation. 1996: WHO integration of health care delivery. WHO Technical Report Series 861, $1-68$.

World Health Organisation. 1997: WHO integrated management of childhood illnesses. Bulletin of the WHO 75 (Suppl 1), 1-128.

WHO Expert Consultation. 2004: Appropriate bodymass index for Asian populations and its implications for policy and intervention strategies. The Lancet 363, $157-63$. 